\title{
Structural and Electrical Properties of $\mathrm{Bi}_{3} \mathbf{Y}_{0.9} \mathrm{~W}_{0.1} \mathrm{O}_{6.15}$ -
}

\section{$\mathrm{La}_{0.8} \mathrm{Sr}_{0.2} \mathrm{MnO}_{3}(\mathrm{BiYWO}-\mathrm{LSM})$ Composites}

M. Dudz, ${ }^{1}$ W. Wrobel, ${ }^{1 *}$ M. Malys, ${ }^{1}$ A. Borowska-Centkowska, ${ }^{1}$ I. Abrahams, ${ }^{2}$ K-Z. Fung $^{3}$ and F. Krok ${ }^{1}$

${ }^{1}$ Faculty of Physics, Warsaw University of Technology, Koszykowa 75, 00-662 Warszawa, Poland

${ }^{2}$ Materials Research Institute, School of Biological and Chemical Sciences, Queen Mary University of London, Mile End Road, London E1 4NS, UK

${ }^{3}$ Material Science and Engineering, National Cheng Kung University, 1\# University Road, Tainan, Taiwan

wrobel@if.pw.edu.pl

Keywords:

SOFC; SOFC cathode; composite material; mixed ionic - electronic conductivity; transference numbers; bismuth oxide; X-ray diffraction; ac impedance spectroscopy. 


\begin{abstract}
Electrical conductivity and structural behavior in $\mathrm{Bi}_{3} \mathrm{Y}_{0.9} \mathrm{~W}_{0.1} \mathrm{O}_{6.15}-\mathrm{La}_{0.8} \mathrm{Sr}_{0.2} \mathrm{MnO}_{3}$ (BiYWOLSM) composite cathodes for intermediate temperature solid-oxide fuel cells (IT-SOFCs) have been investigated. The ionically conducting component (BiYWO) was selected as it not only exhibits high oxide ion conductivity at intermediate temperatures, but also shows good long-term stability. The LSM component is a well-known electronic conductor, commonly used for SOFC cathodes and also shows high interfacial polarization effects. Both composite components exhibit similar thermal expansion coefficients. Composites of different molar ratios of components were prepared by sintering the components together at $850{ }^{\circ} \mathrm{C}$. Electrical behavior was studied by a.c. impedance spectroscopy and transference number measurements were used to determine the ionic and electronic contributions to total conductivity. Percolation type behavior was observed for total conductivity and the percolation threshold value was determined to be in the bismuth rich region of the compositional range, due to the significant difference in the grain sizes of the two components. Ionic and electronic components of the total conductivity at, above and below the percolation threshold are discussed. Stability measurements on a composition close to the percolation threshold show some degree of conductivity decay on prolonged annealing at $650{ }^{\circ} \mathrm{C}$, which is partly recoverable on heating to higher temperatures.
\end{abstract}




\section{Introduction}

Composite multi-phase materials are attracting increasing attention for a variety of applications, since they offer the possibility of designing new materials with tailored properties by simply combining two or more different constituents. One such application is in electrochemical devices, for example composites can be used as cathode materials in solid oxide fuel cells (SOFCs) [1-4]. The oxygen reduction reaction (ORR) in SOFCs occurs at the so called triple phase boundary (TPB), which is the point of contact between gaseous, ionically conducting and electronically conducting phases [5]. Ideally, cathode materials have high porosity and high values of both ionic and electronic conductivity, which enhances the extent of the TPB. This can be achieved in single phase materials such as LSCF $\left(\mathrm{La}_{1-x} \operatorname{Sr}_{x} \mathrm{Co}_{1-}\right.$ $\left.{ }_{y} \mathrm{Fe}_{y} \mathrm{O}_{3-\delta}\right)$ and BSCF $\left(\mathrm{Ba}_{1-x} \mathrm{Sr}_{x} \mathrm{Co}_{0.8} \mathrm{Fe}_{0.2} \mathrm{O}_{3-\delta}\right)$ [6,7], which show mixed ionic-electronic conduction. Multi-phase composite materials have also been considered in this role, with the advantage that the TPB can be extended to the bulk of the material, resulting in a significant reduction of polarization resistance and hence increasing cell efficiency.

Apart from ceramic-metal (CERMET) composites [eg. 8,9], ceramic-ceramic composite cathodes, involving one ceramic component of high ionic conductivity and another ceramic component of high electronic conductivity have also been studied. The ionically conducting component is typically a stabilized zirconia or doped ceria, while the electronic component is typically a perovskite, such as $\mathrm{La}_{0.8} \mathrm{Sr}_{0.2} \mathrm{MnO}_{3}[10,11]$. Bismuth oxide based compounds are known for their exceptionally high oxide ion conductivity at relatively low temperatures $[12,13]$ and would be interesting candidates for composite cathodes. Indeed, pure bismuth oxide exhibits the highest oxide ion conductivity of any known solid. While there has been concern over the use of bismuth oxide based materials in SOFCs, due to their ease of reduction under reduced oxygen partial pressures and poor stability, it has been demonstrated through careful chemical and engineering design, that these compounds can be used successfully in the construction of intermediate temperature solid oxide fuel cells (ITSOFCs) $[14,15]$.

In this paper a new composite material formed of $\mathrm{La}_{0.8} \mathrm{Sr}_{0.2} \mathrm{MnO}_{3}$ and a stabilized $\delta$ bismuth oxide phase $\left(\mathrm{Bi}_{3} \mathrm{Y}_{0.9} \mathrm{~W}_{0.1} \mathrm{O}_{6.15}\right)$ is presented and its electrical and structural properties characterized and discussed. The $\mathrm{Bi}_{3} \mathrm{Y}_{0.9} \mathrm{~W}_{0.1} \mathrm{O}_{6.15}$ composition has been chosen for the present study, because of its enhanced stability compared to other stabilized $\delta$-bismuth oxide phases [16], which show a degree of conductivity decay and structural changes on prolonged annealing at the working temperatures of IT-SOFCs. Tungsten doping into isovalent 
substituted bismuth oxides has been shown to impart greater stability in these systems $[17,18]$.

\section{Experimental}

\subsection{Sample preparations}

$\mathrm{Bi}_{3} \mathrm{Y}_{0.9} \mathrm{~W}_{0.1} \mathrm{O}_{6.15}$ (BiYWO) was prepared by solid-state reaction of the parent oxides. Stoichiometric amounts of $\mathrm{Bi}_{2} \mathrm{O}_{3}$ (Sigma Aldrich, 99.9\%), $\mathrm{Y}_{2} \mathrm{O}_{3}$ (Sigma Aldrich, 99.99\%) and $\mathrm{WO}_{3}$ (Sigma Aldrich, 99.99\%) were ground in ethanol using a planetary ball mill for ca. $12 \mathrm{~h}$. The dried mixture was heated in air at $700{ }^{\circ} \mathrm{C}$ for $24 \mathrm{~h}$, then cooled and reground in an agate mortar. The sample was then heated at $750{ }^{\circ} \mathrm{C}$ for $24 \mathrm{~h}$ and quenched to room temperature. $\mathrm{La}_{0.8} \mathrm{Sr}_{0.2} \mathrm{MnO}_{3}$ (LSM) was prepared using a glycine-nitrate method with $\mathrm{La}\left(\mathrm{NO}_{3}\right)_{3}, \mathrm{Sr}\left(\mathrm{NO}_{3}\right)_{2}$ and $\mathrm{Mn}\left(\mathrm{NO}_{3}\right)_{2}$ as precursors following the procedure presented by Tsai et al. [19].

BiYWO and LSM were mixed at various volume ratios $(0 \leq f \leq 1)$, defined by the

parameter $f=\frac{\text { BiYWO phase volume }}{\text { composite volume }}$, where the phase volume was based on the crystallographic density derived by Rietveld analysis and the composite volume was a weighted sum of the individual phase volumes. The mixtures were ground together in an agate mortar in acetone with a drop of polyethylene glycol 400 , dried and pelletized. Pellets were pressed isostatically at a pressure of $400 \mathrm{MPa}$ and heated to $850{ }^{\circ} \mathrm{C}$ for $10 \mathrm{~h}$. Sample density was measured by the Archimedes method in isobutanol and compared with the theoretical crystallographic density, derived by Rietveld analysis, for the relative density determination.

\subsection{Electrical measurements}

Electrical parameters were determined by a.c. impedance spectroscopy up to $\mathrm{ca} .800{ }^{\circ} \mathrm{C}$, using a fully automated Novocontrol alpha- $\mathrm{N}$ frequency response analyzer, in the frequency range $0.1 \mathrm{~Hz}$ to $2 \times 10^{7} \mathrm{~Hz}$. Samples for impedance measurements were prepared as rectangular blocks $\left(c a .8 \times 3 \times 3 \mathrm{~mm}^{3}\right)$ cut from quenched sintered pellets using a diamond saw. Platinum electrodes were sputtered by cathodic discharge on the two smallest faces. Impedance spectra were acquired over two cycles of heating and cooling at stabilized temperatures. Impedance at each frequency was measured repeatedly until consistency ( $2 \%$ tolerance in drift) was achieved or a maximum number of three repeats had been reached, using an algorithm described earlier [20].

The total conductivity of the $f=0.81$ sample, as measured by a.c. impedance spectroscopy, was monitored during long-term isothermal annealing at $650{ }^{\circ} \mathrm{C}$ in $50 \mathrm{~min}$ 
intervals for $c a .210 \mathrm{~h}$. To minimize electrode degradation during long-term annealing $[21,22]$, sputtered gold electrodes were used.

The ionic and electronic contributions to the total conductivity were measured using a modified EMF method, with an external adjustable voltage source in the concentration cell $\mathrm{O}_{2}\left(\mathrm{pO}_{2}=1.01 \times 10^{5} \mathrm{~Pa}\right): \mathrm{Pt} \mid$ sample $\mid \mathrm{Pt}: \mathrm{O}_{2}\left(\mathrm{pO}_{2}=0.2095 \times 10^{5} \mathrm{~Pa}\right)$, as described in detail elsewhere [23]. Measurements were performed on cooling between $c a .800{ }^{\circ} \mathrm{C}$ and $c a .500{ }^{\circ} \mathrm{C}$ at stabilized temperatures for selected composites $(0.75 \leq f \leq 1)$.

\subsection{Diffraction}

X-ray powder diffraction (XRD) data were obtained on a Philips X'Pert Pro diffractometer fitted with an $\mathrm{X}^{\prime}$ Celerator detector, using Ni filtered $\mathrm{Cu}-\mathrm{K} \alpha$ radiation $\left(\lambda_{1}=1.54056 \AA\right.$ and $\lambda_{2}$ $=1.54439 \AA$ ). Data were collected in flat plate $\theta / \theta$ geometry and calibrated against an external $\mathrm{LaB}_{6}$ standard. Room temperature data suitable for detailed Rietveld refinement were collected in the $2 \theta$ range $5-105^{\circ}$, in steps of $0.0167^{\circ}$, with an effective scan time of $400 \mathrm{~s}$ per step. Elevated temperature measurements were made using an Anton Paar HTK-1200N camera. Samples were mounted on a Pt coated ceramic sample holder and data collected in steps of $50^{\circ} \mathrm{C}$, from $50{ }^{\circ} \mathrm{C}$ to $850{ }^{\circ} \mathrm{C}$, in the $2 \theta$ range $5-105^{\circ}$, with a step width of $0.0334^{\circ}$ and an effective scan time of $50 \mathrm{~s}$ per step. Unit cell parameters were determined by Rietveld analysis using the GSAS suite of programs [24]. A cubic model in space group $F m-3 m$ was used for all refinements of the BiYWO phase [20]. Refinement of the LSM phase was carried out using the structure reported by Pinsard et al. in space group Pbnm [25].

\subsection{Morphology and Thermal analysis}

Morphological characterization of prepared samples was carried out with a Raith e-Line plus scanning electron microscope. Combined differential thermal analysis and thermogravimetric analysis (DTA/TGA) was carried out using a TA Instruments Q600. Approximately $30 \mathrm{mg}$ of powdered sample in an alumina crucible was monitored over heating and cooling cycles, between ambient temperature and $1000{ }^{\circ} \mathrm{C}$, at a heating rate of $20^{\circ} \mathrm{C} \mathrm{min}^{-1}$ in flowing air.

\section{Results and Discussion}

\subsection{Composite structure}

Room temperature XRD patterns for the studied BiYWO-LSM composites are presented in Fig. 1a. In the composition range $0.6 \leq f \leq 1$, diffraction patterns show a simple mixture of 
individual BiYWO and LSM phases, with no evidence of additional phases. For the LSM rich composites $(f<0.6)$, a small amount of an additional rhombohedral phase is visible. The diffraction peaks of this phase show a good match to those of $\mathrm{Bi}_{0.775} \mathrm{La}_{0.225} \mathrm{O}_{1.5}$ (BLO, PDF No. 00-048-0346). However, since this phase is part of a solid solution in the $\mathrm{Bi}_{2} \mathrm{O}_{3}-\mathrm{La}_{2} \mathrm{O}_{3}$ system [26,27], its exact stoichiometry cannot be stated unambiguously. Moreover, since an isostructural phase is known to occur in the $\mathrm{Bi}_{2} \mathrm{O}_{3}-\mathrm{Y}_{2} \mathrm{O}_{3}$ system [28], one cannot exclude the possibility that this is a bismuth yttrate phase or even a mixed yttrate/lanathanate phase. It is likely that this phase occurs at the BiYWO/LSM interface, but there is no direct evidence for this in the SEM images. Growth of interfacial secondary phases is seen in other composite materials, for example in the LSM-YSZ (yttria-stabilized zirconia) composite, where $\mathrm{La}_{2} \mathrm{Zr}_{2} \mathrm{O}_{7}$ and $\mathrm{SrZrO}_{3}$ phases are observed at the YSZ/LSM interface [4].

Fig. 1b shows the compositional variation of unit cell volume for the BiYWO and LSM phases. It can be seen that the unit cell volume of the BiYWO phase increases with increasing $f$ value up to around 0.75 , above which the volume remains fairly constant. This indicates that the $\mathrm{BiYWO}$ phase is $\mathrm{Bi}$ poor at low values of $f$, consistent with partial reaction of the BiYWO phase to form BLO at these compositions. Above $f=0.75$ the constant volume of the BiYWO phase suggests no significant reaction between BiWYO and LSM as evidenced by the X-ray diffraction data.

a)

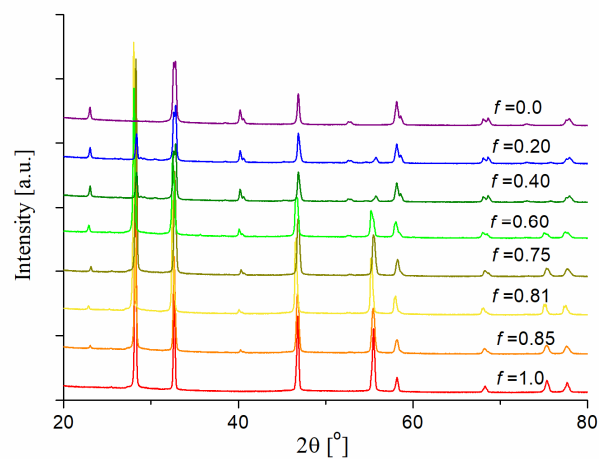

b)

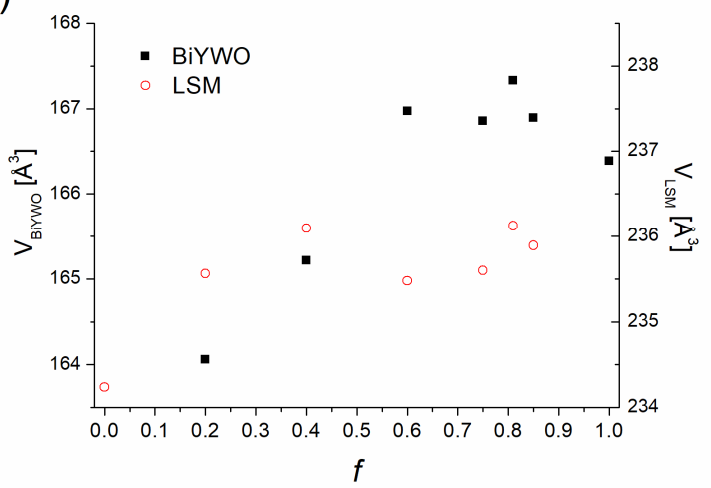

Fig. 1. (a) X-ray diffraction patterns for BiYWO-LSM composites and (b) compositional dependence of unit cell volume for BiYWO and LSM phases at ambient temperature.

The thermal variation of unit cell volume for the BiYWO and LSM phases in a representative composite $(f=0.81)$ is shown in Fig. 2, with similar plots obtained for other $f$-value composites. It can be seen that the two plots are virtually parallel suggesting good matching of thermal expansion for the two component phases. At about $550{ }^{\circ} \mathrm{C}$ the plots show a change in slope, with the volumes at higher temperatures slightly larger than predicted by a simple 
linear extrapolation of the low temperature data. This is consistent with a small degree of reduction in both cases. The linear thermal expansion coefficients were calculated as $\alpha=$ $\frac{1}{3 V} \frac{\Delta V}{\Delta T}$, while $\frac{\Delta V}{\Delta T}$ was obtained from the slope of a linear fit to the data in Fig. 2. TEC values below and above $550{ }^{\circ} \mathrm{C}$ were respectively $13.9 \times 10^{-6} \mathrm{~K}^{-1}$ and $20.3 \times 10^{-6} \mathrm{~K}^{-1}$ for the BiYWO phase and $14.4 \times 10^{-6} \mathrm{~K}^{-1}$ and $17.9 \times 10^{-6} \mathrm{~K}^{-1}$ for the LSM phase. The TEC values for LSM are close to values reported in the literature [29]

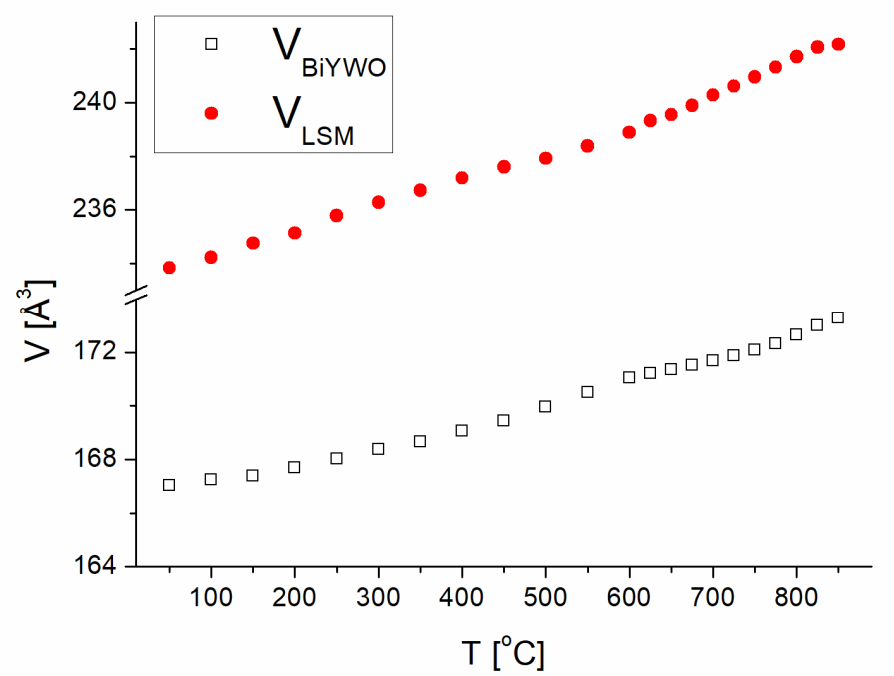

Fig. 2. Thermal variation of unit cell volume for the BiYWO and LSM phases in the $f=0.81$ composite.

The DTA/TGA curves for an unsintered mixture of BiYWO and LSM corresponding to $f=0.75$ is shown in Fig. 3. The exothermic peak with an onset at $210{ }^{\circ} \mathrm{C}$ and mass loss of ca. $2 \%$ is associated with the flash point of the polyethelene glycol. There are no other features to indicate a reaction between LSM and BiYWO components over the studied temperature range. 


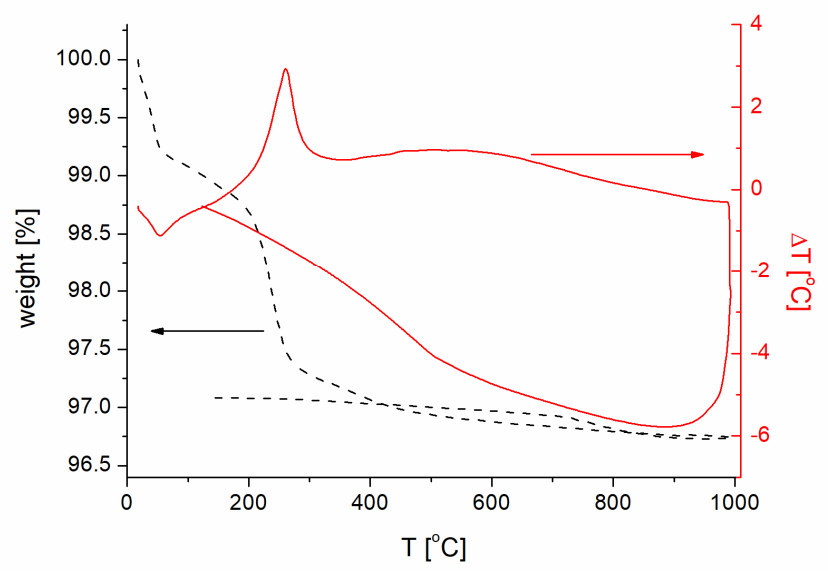

Fig. 3. DTA/TGA curves for $f=0.75$ composite.

\subsection{Total electrical conductivity}

Total electrical conductivity data for the studied composites are presented as Arrhenius type plots in Fig. 4. The pure BiYWO $(f=1)$ sample shows high values of oxide ion conductivity at intermediate temperatures $\left(0.032 \mathrm{~S} \mathrm{~cm}^{-1}\right.$ at $500{ }^{\circ} \mathrm{C}$, rising to $0.318 \mathrm{~S} \mathrm{~cm}^{-1}$ at $\left.700{ }^{\circ} \mathrm{C}\right)$. As previously reported in many other bismuth oxide based compounds [29,30], the plot shows two linear regions, one at high temperature (above ca. $650{ }^{\circ} \mathrm{C}$ ) and a second at lower temperature (below ca. $500{ }^{\circ} \mathrm{C}$ ), with activation energies of around 0.6 and $1.2 \mathrm{eV}$, respectively. The two regions are separated by a curved non-Arrhenius region. The change of the activation energy in the BiYWO component, as well as in other bismuth oxide based compounds, is commonly attributed to an order-disorder transition in the oxygen sublattice and is usually correlated with a change in the thermal expansion coefficient (Fig. 2). The pure $\operatorname{LSM}(f=0)$ sample shows high electronic conductivity $\left(10.2 \mathrm{~S} \mathrm{~cm}^{-1}\right.$ at $\left.700{ }^{\circ} \mathrm{C}\right)$ and low activation energy $(0.11 \mathrm{eV})$ [31]. It should be noted, that the conductivity of LSM measured in this work is significantly lower than that reported in the literature $\left(160 \mathrm{~S} \mathrm{~cm}^{-1}\right.$ at $\left.700{ }^{\circ} \mathrm{C}\right)$ [4]. This is attributed to the low sintering temperature used to prepare the composites which is optimized for the BiYWO phase, with higher temperatures resulting in excessive loss of volatile $\mathrm{Bi}_{2} \mathrm{O}_{3}$. This results in relatively low overall densities for the composites (e.g. 5.80, 6.62 and $7.14 \mathrm{~g} \mathrm{~cm}^{-3}$ for the $f=0, f=0.81$ and $f=1$ compositions, respectively), with relative density ranging from $87 \%$ to $93 \%$ for $f=0$ to $f=1$, respectively. The issue of the influence of sintering temperature on total electrical conductivity in other LSM based composites has been discussed extensively, for example in LSM-scandia-ceria-zirconate composites [32].

In Fig. 4 two groups of composites can be considered: those with low $(f<0.8)$ and those with high $(f>0.8)$ BiYWO phase content. Electrical properties of the first group are 
dominated by the LSM component, with very high total conductivity and low activation energy over the studied temperature range. It should be noted, that for the composite $f=0.75$, with an LSM content of only $25 \% \mathrm{v} / \mathrm{v}$, total conductivity is not much lower than that for pure $\operatorname{LSM}$ ( $c a$. half an order of magnitude at $800{ }^{\circ} \mathrm{C}$ and $c a$. one order of magnitude at $25^{\circ} \mathrm{C}$ ). For composites with higher BiYWO fractions $(0.8<f<0.95)$, at high temperatures, conductivity shows features characteristic of pure BiYWO, including high activation energies and nonArrhenius behavior. However, at lower temperatures, a low activation energy, characteristic of the electronically conducting LSM phase, is observed. In this composition range, even small differences in the $f$ parameter result in a significant conductivity change at low temperatures.

For the composites with the highest BiYWO phase fractions $(f>0.95)$, conductivity plots are parallel to that of pure BiYWO, over the studied temperature range. Interestingly, total conductivity values of the $f>0.95$ composites are slightly lower than those for pure BiYWO $(f=1)$. This is due to the effect of small volumes of the LSM phase in the composites, which serve to break up the ionic conduction pathways between the BiYWO grains.

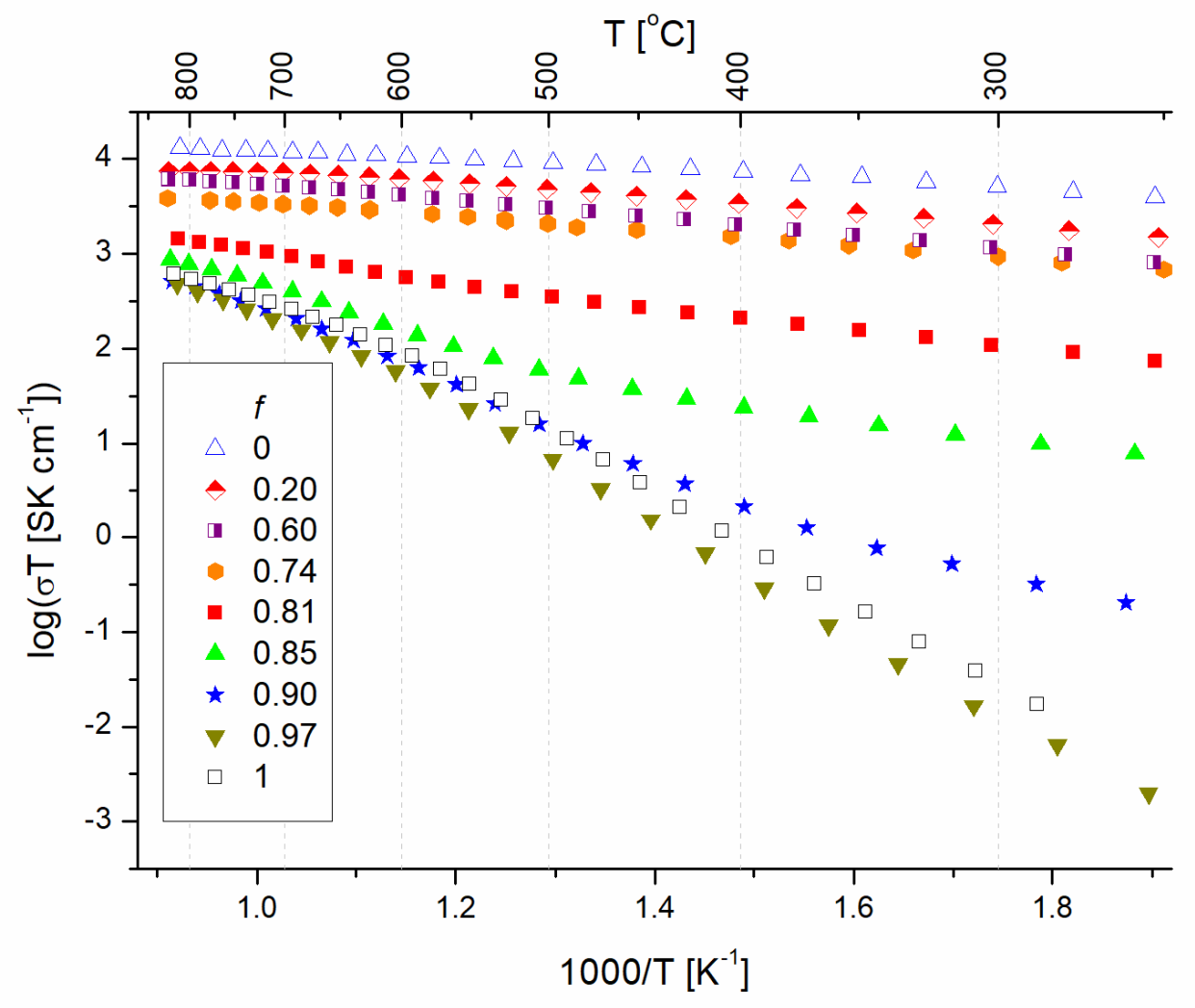

Fig. 4. Arrhenius type plots of total conductivity for BiYWO-LSM composites. Estimated errors are $\pm 5 \%$ on $\sigma$. 


\subsection{Transference number measurements}

Since the total electrical conductivity data for studied composites show some features characteristic of both electronic and ionic conductivity, transference number measurements were performed for selected composites $0.75 \leq f<1$. It should be noted, that the applied method of transference number determination, based on EMF measurements under an oxygen partial pressure gradient, is limited to temperatures between $c a .450$ and $850{ }^{\circ} \mathrm{C}$ [23]. Fig. 5 presents total conductivity as well as its ionic and electronic contributions for two characteristic compositions. In the case of the $f=0.81$ composite, in the studied temperature range, total conductivity is dominated by the electronic conductivity and the ionic component of total conductivity is more than 1 order of magnitude lower than the electronic component (Fig. 5a). For the $f=0.9$ composite, the ionic component dominates total conductivity, with the electronic conductivity $c a$. 1 order of magnitude lower than the ionic conductivity (Fig. $5 b)$.

The temperature dependence of electronic conductivity for selected composites is presented in Fig. 6 . For the $0.75 \leq f \leq 0.81$ composition range, electronic conductivity is much higher than ionic conductivity and thus these composites can be considered as predominantly electronic conductors. The electronic conductivity of composites gradually decreases with decreasing LSM content (increasing $f$ parameter) up to $f=0.81$. Above this threshold value, a sharp drop in electronic conductivity is observed ( 1 and 2 orders of magnitude at $c a .800{ }^{\circ} \mathrm{C}$ and $c a .450{ }^{\circ} \mathrm{C}$, respectively), decreasing to values much smaller than those of the ionic conductivity, and therefore composites above this threshold value are predominantly ionic conductors.

For the $f \leq 0.81$ composites, the values of activation energy of electronic conductivity determined from transference number measurements, $\Delta E_{\text {ele }}$, are around $0.3 \mathrm{eV}$ and are similar to the values for activation energy of total conductivity, $\Delta E_{\mathrm{tot}}$, of $c a .0 .2 \mathrm{eV}$, determined from a.c. impedance spectroscopy measurements (Fig. 4) over the corresponding temperature ranges. These low $\Delta E_{\text {ele }}$ values are typical for the LSM phase [11,31]. For composites with a high BiYWO volume fraction $(f>0.81)$, the values for $\Delta E_{\text {ele, }}$ of $1.0-1.2 \mathrm{eV}$ at $450-550{ }^{\circ} \mathrm{C}$, are significantly higher than those for composites below the threshold value and are similar to the activation energy for total conductivity in pure BiYWO.

The results suggest that below the threshold value, charge transport occurs mostly through the LSM phase and therefore is predominantly electronic in nature, whereas above the threshold value the pathways through the LSM phase are broken and the charge transport 
occurs mainly through the BiYWO phase and is therefore predominantly via ionic conductivity.

(a)

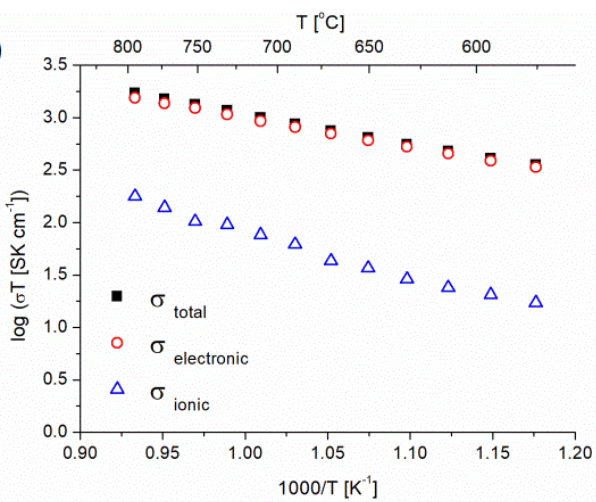

(b)

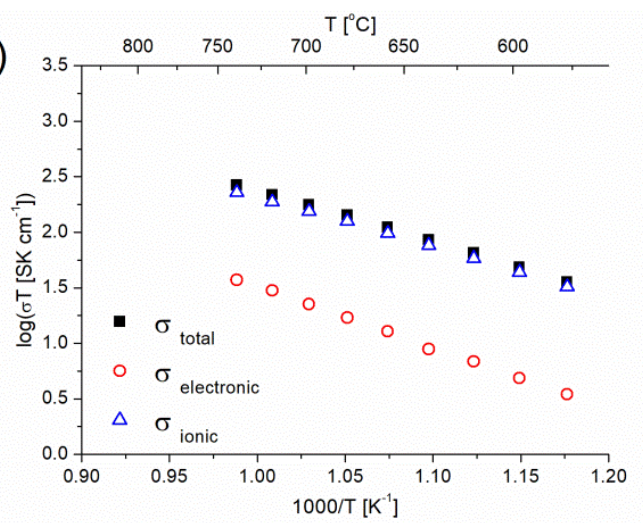

Fig. 5. Ionic and electronic components of total conductivity for (a) $f=0.81$ and (b) $f=0.9$ BiYWO-LSM composites.

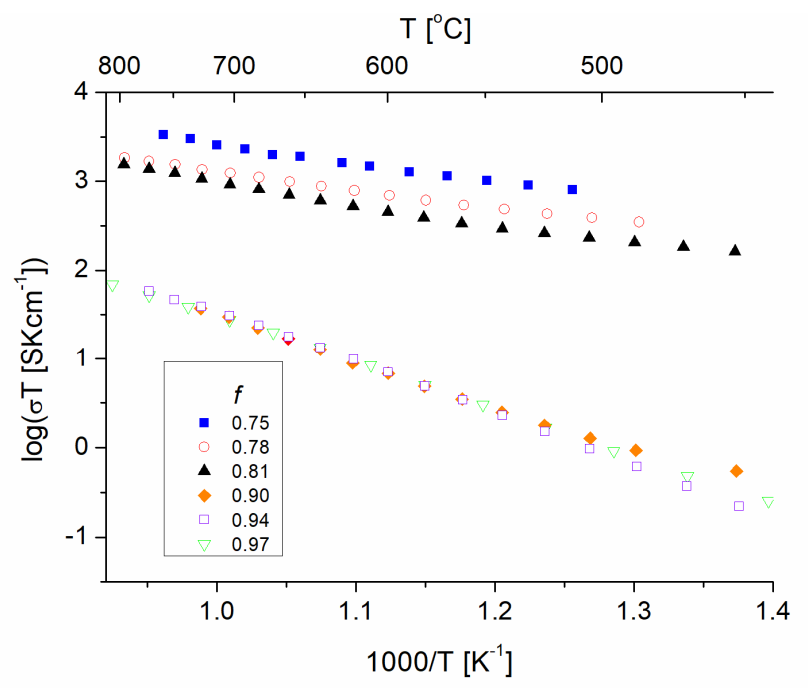

Fig. 6. Arrhenius type plots of the electronic component of total conductivity for BiYWO-LSM composites.

\subsection{Percolation threshold}

The presence of a threshold composition, where the electrical properties of the composites abruptly change, is indicative of percolation type behavior. Total conductivity data at selected temperatures are presented as a function of BiYWO phase content in Fig. 7. The data were fitted using the Generalized Effective Medium Theory (GEMT) model [33], which has previously been successfully applied to ionic-electronic ceramic and cermet composites [34- 
36]. The percolation threshold, $f_{c}$, obtained from the fitted model is the same for all data irrespective of temperature and is equal to 0.83 .

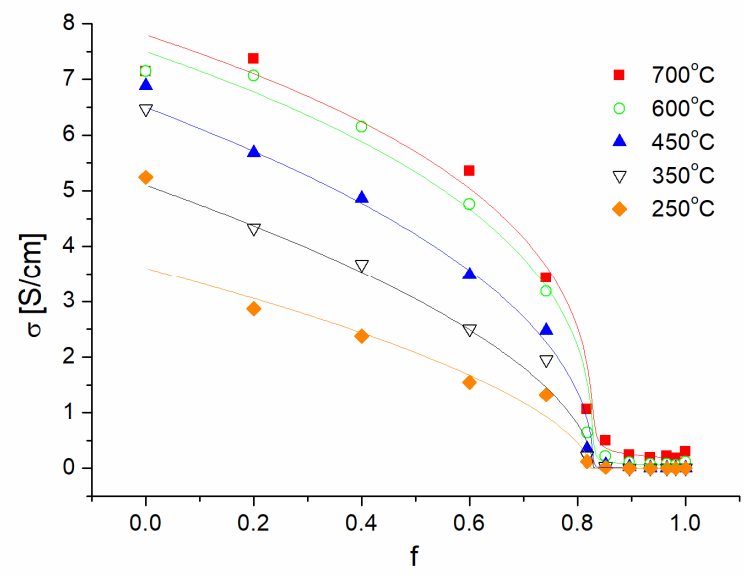

Fig. 7. Percolation curves for total conductivity in BiYWO-LSM composites. Solid lines are GEMT model curves fitting experimental data points (symbols) at different temperatures.

In terms of the GEMT model, the percolation threshold can be considered as a composition, for which conduction pathways through both phases of the composite are continuous throughout the sample. The high value of the percolation threshold in the studied system is related to the significant difference in grain sizes of the BiYWO and LSM phases, which is clearly seen in SEM images (Fig. 8). The BiYWO phase exhibits large grains (ca. 2$5 \mu \mathrm{m}$ ), while the grains of LSM are significantly smaller (ca. 200-500 nm). It is known, that the percolation threshold can change significantly depending on component grain sizes and is usually close to 0.5 for equal size grains [37]. Thus, for compositions below the threshold value, continuous pathways are visible only for the LSM phase, for example as seen in the SEM image for the $f=0.75$ composite (Fig. 8a). In contrast, in Fig. 8b, which is an image of a composition close to the percolation threshold $(f=0.85)$, conduction pathways are visible for both LSM and BiYWO phases.

(a)

(b) 

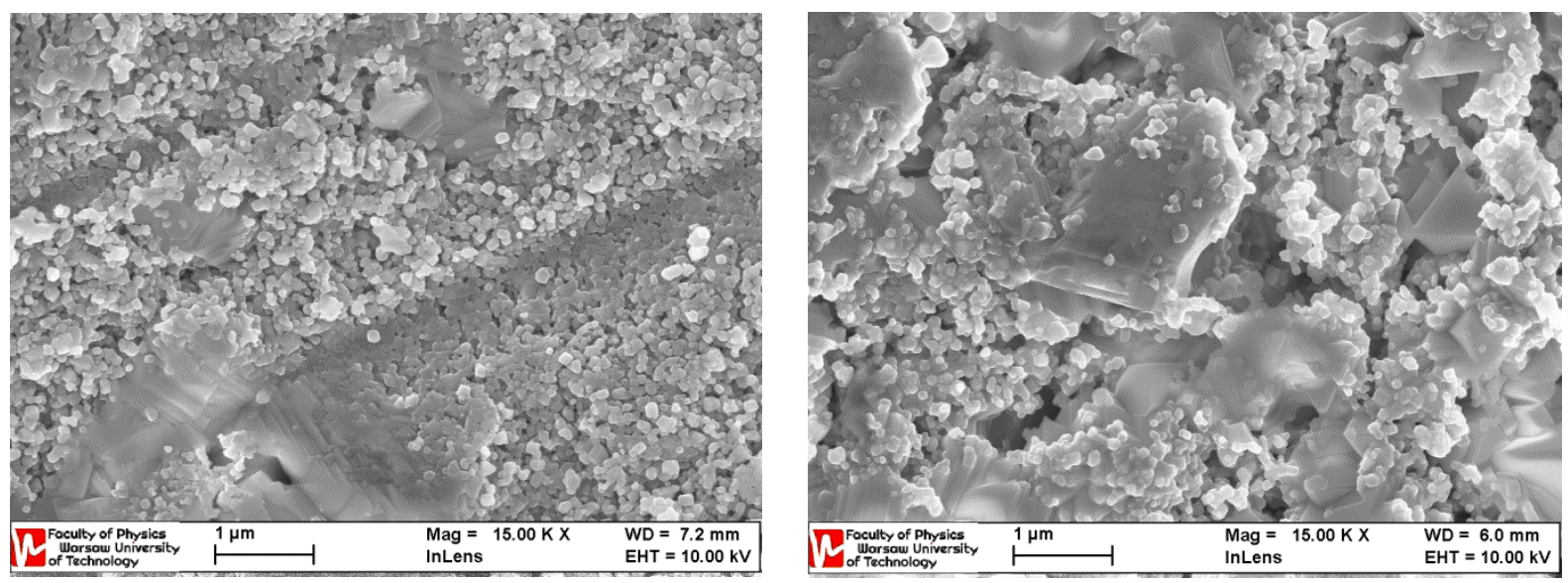

Fig. 8. SEM images for (a) $f=0.75$ and (b) $f=0.85$ composites of BiYWO-LSM system.

\subsection{Stability}

Conductivity changes on prolonged annealing at $650{ }^{\circ} \mathrm{C}$ were monitored for $c a .200 \mathrm{~h}$ for the $f=0.81$ composite. Conductivity decreases by $c a$. $30 \%$ and reaches a nearly steady-state by $200 \mathrm{~h}$ (Fig. 3). After reheating to $780{ }^{\circ} \mathrm{C}$ and above, conductivity recovers to around $85 \%$ of the initial value. While, this type of conductivity decay is commonly observed in bismuth oxide based compounds [16,38,39] and has been attributed to ordering processes in the oxygen sublattice, in the present study transference number measurements show the ionic conductivity to be approximately an order of magnitude lower than electronic conductivity in this composition. In addition previous work has shown that the BiYWO composition is particularly stable [16]. LSM is also known for its stability [40,41] and hence the observed conductivity decay must be associated with a particular feature of the composite itself, i.e. the BiYWO/LSM interface. The observation of a rhombohedral phase in LSM rich compositions represents a clue to the behavior of the BiYWO/LSM interface. It is known that the rhombohedral phase often appears in bismuth oxides like $\mathrm{Bi}_{3} \mathrm{YO}_{6}$ on prolonged annealing at around $600{ }^{\circ} \mathrm{C}$ [28]. The appearance of a secondary electronically insulating phase at the BiYWO/LSM interface, would be expected to lower the total conductivity by breaking up the conduction pathways through the composite. Although X-ray diffraction results show no evidence of a secondary phase after long-term annealing, the presence of a secondary phase at the grain interfaces cannot be excluded, since small amounts would be beyond the detection limits of X-ray powder diffraction, but would be sufficient to cause the observed conductivity decay. Similarly, if the coherence length of the secondary phase regions was small, then no Bragg peaks would be evident in the diffraction patterns. 


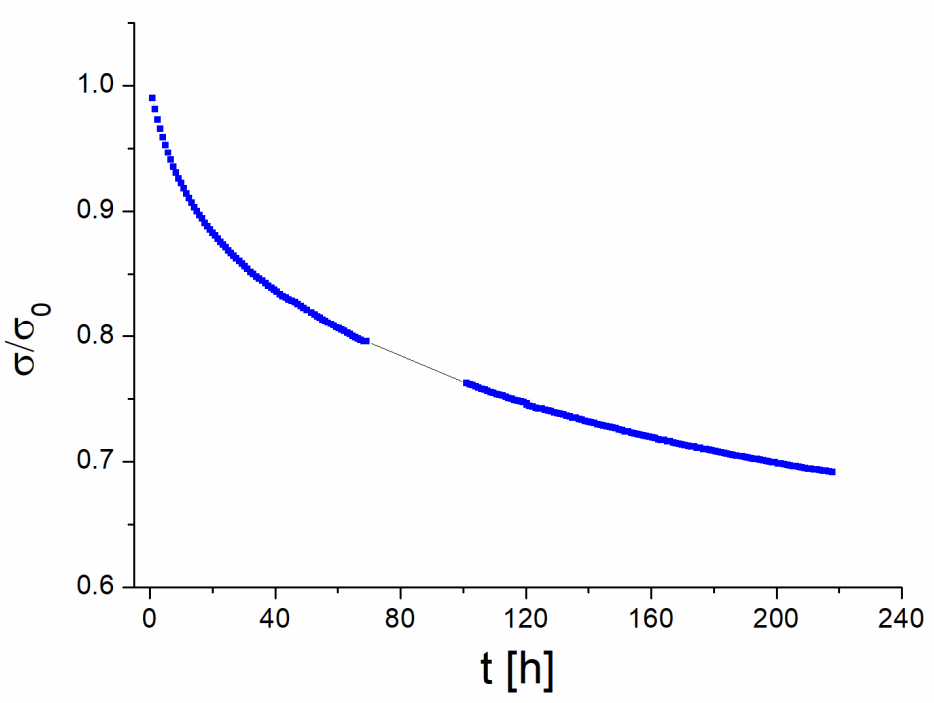

Fig. 9. Relative conductivity on prolonged annealing of the $f=0.81$ composite at $650{ }^{\circ} \mathrm{C}$.

\section{Conclusions}

The electronic conductor LSM $\left(\mathrm{La}_{0.8} \mathrm{Sr}_{0.2} \mathrm{MnO}_{3}\right)$ and the ionic conductor BiYWO $\left(\mathrm{Bi}_{3} \mathrm{Y}_{0.9} \mathrm{~W}_{0.1} \mathrm{O}_{6.15}\right)$ were prepared as composites at various volume ratios. The electrical properties including total, ionic and electronic conductivity of the composites varied as a function of volume fraction of the components. Composites with high BiYWO content exhibit predominantly ionic conductivity, whereas LSM rich composites show high conductivity and low activation energies characteristic of electronic conductors. Percolation type behavior is observed with a threshold value of $f_{c}=0.83$, on the BiYWO rich side of the compositional range. This relatively high threshold value is typical for composites where the components have significantly different grain sizes. Total conductivity of a composition close to the threshold value showed a $30 \%$ decay on prolonged annealing at $650{ }^{\circ} \mathrm{C}$, but recovered to $85 \%$ of the initial value on reheating to higher temperatures. These initial results suggest that electrical behavior can be compositionally tuned in BiYWO-LSM composites. Further work is required to optimize the performance of these materials through microstructure control.

\section{Acknowledgements}

This work was supported by the National Centre for Research and Development Poland under grant number DKO/PL-TW1/6/2013.

\section{References}


[1] M. Camaratta, E. Wachsman, J. Electrochem. Soc. 155 (2008) B135-B142.

[2] E.N. Armstrong, K.L. Duncan, D.J. Oh, J.F. Weaver, E.D. Wachsman, J. Electrochem. Soc. 158 (2011) B492-B499.

[3] S.B. Adler, Chem. Rev. 104 (2004) 4791-4843.

[4] Y. Ji, J.A. Kilner, M.F. Carolan, Solid State Ionics 176 (2005) 937-943.

[5] P. Leone, M. Santarelli, P. Asinari, M. Calì, R. Borchiellini, J. Power Sources 177 (2008) 111-122.

[6] K. Lu, F. Shen, Int. J. Hydrogen Energy 39 (2014) 7963-7971.

[7] Z. Shao, S.M. Haile, Nature 431 (2004) 170-173.

[8] M.A. Camaratta, E.D. Wachsman, Solid State Ionics 178 (2007) 1242-1247.

[9] C. Sun, R. Hui, J. Roller, J. Solid State Electrochem. 14 (2010) 1125-1144.

[10] V. Dusastre, J.A. Kilner, Solid State Ionics 126 (1999) 163-174.

[11] A. Berenov, H. Wood, A. Atkinson, in:, ECS Trans., ECS, 2007, pp. 1173-1181.

[12] N.M. Sammes, G. a. Tompsett, H. Näfe, F. Aldinger, J. Eur. Ceram. Soc. 19 (1999) $1801-1826$.

[13] E.D. Wachsman, K.T. Lee, Science (80-. ). 334 (2011) 935-939.

[14] A. Jaiswal, C. Hu, E.D. Wachsman, J. Electrochem. Soc. 154 (2007) B1088-B1094.

[15] M.A. Camaratta, E.D. Wachsman, Solid State Ionics 178 (2007) 1411-1418.

[16] A. Borowska-Centkowska, M. Leszczynska, W. Wrobel, M. Malys, S. Hull, S.T. Norberg, F. Krok, I. Abrahams, Solid State Ionics (n.d.).

[17] D.W. Jung, K.T. Lee, E.D. Wachsman, J. Korean Ceram. Soc. 51 (2014) 260-264.

[18] S.-H. Jung, E.D. Wachsman, N. Jiang, Ionics (Kiel). 8 (2002) 210-214.

[19] S.-Y. Tsai, K.-Z. Fung, C.-T. Ni, Y.-F. Chang, ECS Trans. 68 (2015) 867-874.

[20] J.R. Dygas, M. Malys, F. Krok, W. Wrobel, A. Kozanecka, I. Abrahams, Solid State Ionics 176 (2005) 2085-2093.

[21] J. Nielsen, T. Jacobsen, Solid State Ionics 178 (2007) 1001-1009.

[22] J.-Y. Park, E.D. Wachsman, Ionics (Kiel). 12 (2006) 15-20.

[23] M. Malys, J.R. Dygas, M. Holdynski, A. Borowska-Centkowska, W. Wrobel, M. Marzantowicz, Solid State Ionics 225 (2012) 493-497.

[24] A.C. Larson, R.B. von Dreele, General Structure Analysis System (GSAS), 2004.

[25] L. Pinsard, J. Rodriguez-Carvajal, A. Revcolevschi, J. Alloys Compd. 262-263 (1997) $152-156$.

[26] Y. Zhang, H. Wang, Y. Hou, S.X. Shang, X.H. Xu, M. Wang, S.K. Qi, J. Mater. Sci. Lett. 22 (2003) 345-347. 
[27] H. Iwahara, T. Esaka, T. Sato, T. Takahashi, J. Solid State Chem. 39 (1981) 173-180.

[28] A. Watanabe, Solid State Ionics 86-88 (1996) 1427-1430.

[29] B. Steele, Solid State Ionics 129 (2000) 95-110.

[30] T.H. Etsell, S.N. Flengas, Chem. Rev. 70 (1970) 339-376.

[31] F. Tietz, I. Arul Raj, M. Zahid, D. Stöver, Solid State Ionics 177 (2006) 1753-1756.

[32] V. Sadykov, G. Alikina, A. Lukashevich, V. Muzykantov, V. Usoltsev, A. Boronin, S. Koscheev, T. Krieger, A. Ishchenko, A. Smirnova, O. Bobrenok, N. Uvarov, Solid State Ionics 192 (2011) 540-546.

[33] D.S. Mclachlan, 20 (1987) 865-877.

[34] J.H. Lee, H. Moon, H.W. Lee, J. Kim, J.D. Kim, K.H. Yoon, Solid State Ionics 148 (2002) 15-26.

[35] R.A. Cutler, D.L. Meixner, Solid State Ionics 159 (2003) 9-19.

[36] M. Marinšek, S. Pejovnik, J. Maček, J. Eur. Ceram. Soc. 27 (2007) 959-964.

[37] X.J. Chen, S.H. Chan, K.A. Khor, Electrochim. Acta 49 (2004) 1851-1861.

[38] A.A. Yaremchenko, V. V Kharton, E.N. Naumovich, A.A. Tonoyan, Mater. Res. Bull. 35 (2000) 515-520.

[39] S.-Y. Tsai, K.-Z. Fung, C.-T. Ni, Y.-F. Chang, ECS Trans. 68 (2015) 867-874.

[40] G. Wang, Y. Bao, Y. Tian, J. Xia, D. Cao, J. Power Sources 195 (2010) 6463-6467.

[41] J.H. Choi, J.H. Jang, J.H. Ryu, S.M. Oh, J. Power Sources 87 (2000) 92-100. 